\title{
Fluid motion and solute distribution around sinking aggregates. II. Implications for remote detection by colonizing zooplankters
}

\author{
Thomas Kiørboe*, Uffe H. Thygesen \\ Danish Institute for Fisheries Research, Kavalergården 6, 2920 Charlottenlund, Denmark
}

\begin{abstract}
Marine snow aggregates are colonized by copepods, and encounter rates inferred from observed abundances of colonizers are high. We examined the potential for hydromechanical and chemical remote detection. The fluid disturbance generated by a sinking aggregate was described by solving the Navier-Stokes' equation for a sinking sphere at Reynolds numbers typical of marine snow (up to 20). Fluid deformation rate, the component of the flow that can be perceived by copepods, attenuates rapidly, and detection distances estimated from knowledge of the hydromechanical sensitivity in copepods are insufficient to account for the observed abundances of colonizers. We next solved the advection-diffusion equation to describe the chemical trail left by a leaking and sinking aggregate. The plume is long and slender and may be detected by a horizontally cruising copepod. From the model of the plume and literature-based estimates of size-dependent aggregate leakage rates of amino acids, we estimate that a threshold sensitivity to amino acids of $0.4 \times 10^{-7} \mathrm{M}$ is required to account for observed abundances of colonizers. This is consistent with knowledge of the amino acid concentrations needed to elicit behavioral responses in copepods.
\end{abstract}

KEY WORDS: Marine snow $\cdot$ Copepods $\cdot$ Remote prey detection $\cdot$ Hydromechanical signals $\cdot$ Chemical signals

Resale or republication not permitted without written consent of the publisher

\section{INTRODUCTION}

Large, fast-sinking marine snow aggregates form by coagulation and other processes in the water column and are believed to be the main vehicles for vertical material transport in the ocean (Fowler \& Knauer 1986). However, aggregates are also degraded in the water column. Bacteria hydrolyse (Smith et al. 1992, Grossart \& Simon 1998) and remineralise (Ploug et al. 1999) aggregated material, and fish and zooplankters feed on aggregates (Lampitt et al. 1993, Larson \& Shanks 1996). Thus, turnover rates of aggregated material may be high, and a substantial fraction of aggregated material may be remineralized before the aggregate leaves the upper mixed layer (Kiørboe 2000).

*E-mail: tk@dfu.min.dk
Degradation processes continue below the mixed layer, and lead to a decline in particle flux with depth (Martin et al. 1987, Pace et al. 1987). Banse (1990) proposed that zooplankton plays a pivotal role in the degradation of aggregates.

Grazing on large aggregates can occur in 2 ways, viz., fish and large zooplankters engulf intact snow aggregates (Larson \& Shanks 1996, Dilling et al. 1998), or smaller zooplankters colonize aggregates and feed on their constituents (Alldredge 1976, Shanks \& Walters 1997). Recent observations collected by divers and submersibles demonstrate that aggregates may house a very abundant fauna of colonizing zooplankters, both within the euphotic zone, and at depth, and that these contribute significantly to the degradation of aggregates (reviewed by Kiørboe 2000). This fauna is dominated by small, mm-sized crustaceans, mainly harpacticoid copepods and poecilostomatoid copepods of 


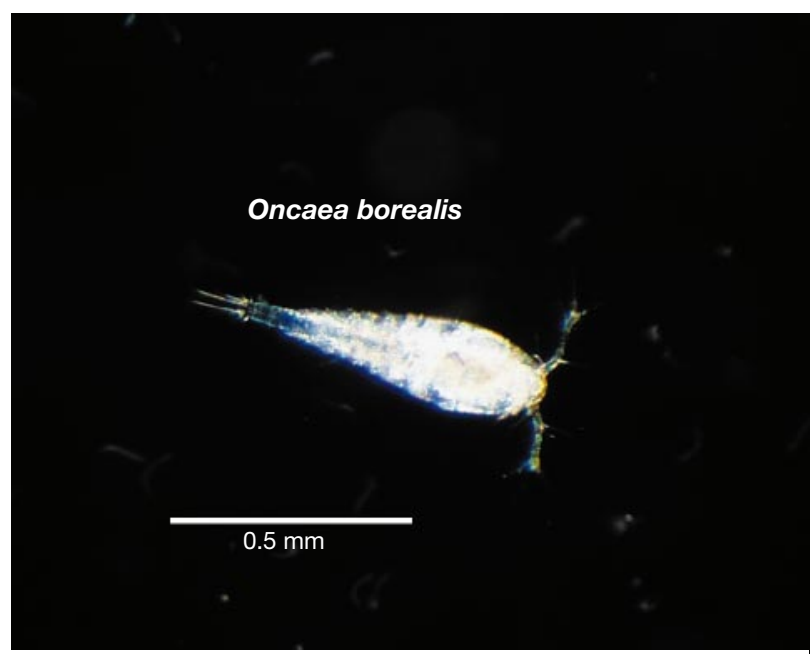

Fig. 1. Oncaea borealis. Copepods of this genus may be found as abundant inhabitants on marine snow aggregates

the genus Oncaea (Fig. 1). Although occurring in the water column, some members of these genera appear to be adapted to a life on solid surfaces (see Paffenhöfer 1993) such as that offered by aggregates. The quantity of colonizing zooplankters observed on aggregates suggest that the zooplankters will have to search substantial volumes of water in order to account quantitatively for the observed association and, therefore, that copepods need to be able to remotely detect aggregates (Kiørboe 2000).

Remote detection may be by chemical or hydromechanical cues, and a sinking aggregate leaking hydrolysation products potentially provides both. A sinking aggregate generates velocity gradients in the ambient water that may be detected by copepods (Fields \& Yen 1997, Kiørboe et al. 1999). Bacteria solubilize aggregated particulate material at a higher rate than at which they assimilate the solutes (Smith et al. 1992, Vetter et al. 1998), and solutes therefore leak out of an aggregate and paint a chemical trail in its wake. Copepods are known to respond behaviorally to organic solutes, particularly amino acids (Poulet \& Ouellet 1982, Gill \& Poulet 1988).

The purpose of this study is to examine whether hydromechanical and/or chemical signals generated by a sinking aggregate may allow remote detection by copepods in a way that can account quantitatively for the observed abundance of colonizing zooplankters on aggregates. We use a model derived from first principles to describe the fluid motion and solute distribution around a sinking sphere and combine model results with what is known about amino acid leakage rates from aggregates and the sensitivity of copepods to amino acids and hydromechanical signals.

\section{THE FLOW AND CONCENTRATION FIELDS}

To characterize the hydrodynamic and chemical signals generated by a sinking aggregate we modeled the aggregate as a rigid sphere sinking at constant speed. The flow is described by solving the Navier-Stokes' equations numerically, and the solute distribution is described by subsequently solving the governing diffusion-advection equation. A full description of the model and of the numerical approach is given in Kiørboe et al. (2001, in this issue). The symbols used here are defined in Table 1.

\section{Flow field}

Following the convention of Karp-Boss et al. (1996) we take the radius of the sphere (a) as the characteristic length, and the sinking velocity of the sphere $(U)$ as the characteristic velocity. Normalization of the Navier-Stokes' equations show that the flow field is then solely a function of the Reynolds number

$$
R e=\frac{a U}{v}
$$

where $v$ is the kinematic viscosity. We have made computations at $R e$ up to 20, which cover the range of $R e$ characteristic of marine snow (Alldredge \& Gotschalk 1988). We computed streamlines and velocity distributions around the falling sphere (Kiørboe et al. 2001). Of particular relevance for hydrodynamic detection of the sinking aggregate is the spatial distribution of the

Table 1. Definition of symbols and standard parameter values used in computations

\begin{tabular}{|c|c|c|c|}
\hline Symbol & Definition & Unit & Default \\
\hline a & Aggregate radius & $\mathrm{cm}$ & - \\
\hline$A$ & $\begin{array}{l}\text { Cross-sectional area of plume with } \\
\text { concentrations exceeding } C^{*}\end{array}$ & $\mathrm{~cm}^{2}$ & - \\
\hline C & Solute concentration & M & - \\
\hline$C^{*}$ & $\begin{array}{l}\text { Threshold concentration for } \\
\text { behavioral resaponse }\end{array}$ & M & $4 \times 10^{-8}$ \\
\hline$D$ & Diffusion coefficient & $\mathrm{cm}^{2} \mathrm{~s}^{-1}$ & $10^{-5}$ \\
\hline$Q$ & $\begin{array}{l}\text { Leakage rate of solutes from } \\
\text { aggregate }\end{array}$ & $\mathrm{mol} \mathrm{s}^{-1} \mathrm{E}$ & Eq. (8) \\
\hline$N_{\mathrm{A}}$ & $\begin{array}{l}\text { Normalized abundance of zoo- } \\
\text { plankters on an aggregate } \mathrm{ml} \mathrm{ag}\end{array}$ & ggregate ${ }^{-1}$ & $e^{-1} \quad-$ \\
\hline$r$ & Copepod equivalent radius & $\mathrm{cm}$ & 0.05 \\
\hline$S$ & Signal strength & $\mathrm{cm} \mathrm{s}^{-1}$ & - \\
\hline$S^{*}$ & Threshold signal strength & $\mathrm{cm} \mathrm{s}^{-1} 4$ & $4 \times 10^{-3}$ \\
\hline$U$ & Aggregate sinking velocity & $\mathrm{cm} \mathrm{s}^{-1}$ & Eq. (7) \\
\hline$v$ & Copepod swimming velocity & $\mathrm{cm} \mathrm{s}^{-1}$ & 0.1 \\
\hline$\beta$ & Encounter volume rate & $\mathrm{cm}^{3} \mathrm{~s}^{-1} \quad \mathrm{E}$ & Eq. (6) \\
\hline$\Delta$ & Maximum deformation rate & $\mathrm{s}^{-1}$ & - \\
\hline$v$ & Kinematic viscosity & $\mathrm{cm}^{2} \mathrm{~s}^{-1}$ & $10^{-2}$ \\
\hline
\end{tabular}




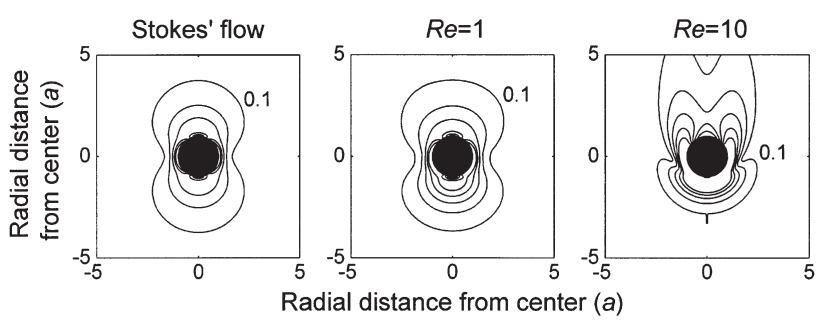

Fig. 2. Spatial distribution of maximum deformation rate. The particle is moving downwards. Distances are in units of radii (a) and deformation isolines are in units of $U / a$ and are spaced by $0.01 \mathrm{U} / \mathrm{a}$ (the outermost labelled isoline)

maximum deformation rate (= maximum component of the stress tensor; see Kiørboe et al. 1999), which was computed numerically. The spatial distribution of deformation rate for $R e \ll 1$ (Stokes' flow), 1, and 10 are shown in Fig. 2. With increasing $R e$, the deformation field becomes compressed upstream of the sphere, elongated downstream, but retains approximately the same width.

\section{Concentration field}

Given the flow field, the concentration field is determined by the Peclet number $(P e)$

$$
P e=\frac{U a}{D}
$$

where $D$ is the diffusion coefficient, and by the leakage rate of solutes from the aggregate $\left(Q, \mathrm{~mol} \mathrm{~s}^{-1}\right)$. The diffusion-advection equation was solved with the outer boundary condition, that far from the sphere the solute concentration approaches the ambient concentration $C_{\infty}$ :

$$
\left.C\right|_{r=\infty}=C_{\infty}
$$

We examined 2 alternative inner boundary conditions by assuming either that the solute concentration is constant over the surface of the sphere (Dirichlet boundary condition):

$$
\left.C\right|_{r=a}=C_{0}
$$

or that the flux is constant over the surface of the sphere (Neumann condition):

$$
\left.\frac{\partial C}{\partial r}\right|_{r=a}=C_{0}
$$

Observations suggest that neither of the 2 alternative boundary conditions accurately apply to marine snow aggregates, but that these describe extremes (Kiørboe et al. 2001).

All computations were made with dimensionless variables and were converted to absolute numbers by inserting absolute (case-specific) values of $U, a$, and $Q$ and in all cases assuming $v=10^{-2} \mathrm{~cm}^{2} \mathrm{~s}^{-1}$ and $D=$ $10^{-5} \mathrm{~cm}^{2} \mathrm{~s}^{-1}$ (characteristic of seawater and amino acids at $20^{\circ} \mathrm{C}$ ).

Examples of computed concentration fields at $P e=0$ (pure diffusion), and $P e=100$, and 10000 (all at $R e=$ $P e / 1000)$ are shown in Fig. 3. With increasing $P e$, the plume becomes increasingly elongated. By $P e=100$ the plume is very long and slender, and concentrations both upstream and to the sides of the sphere drop almost immediately to ambient concentrations.
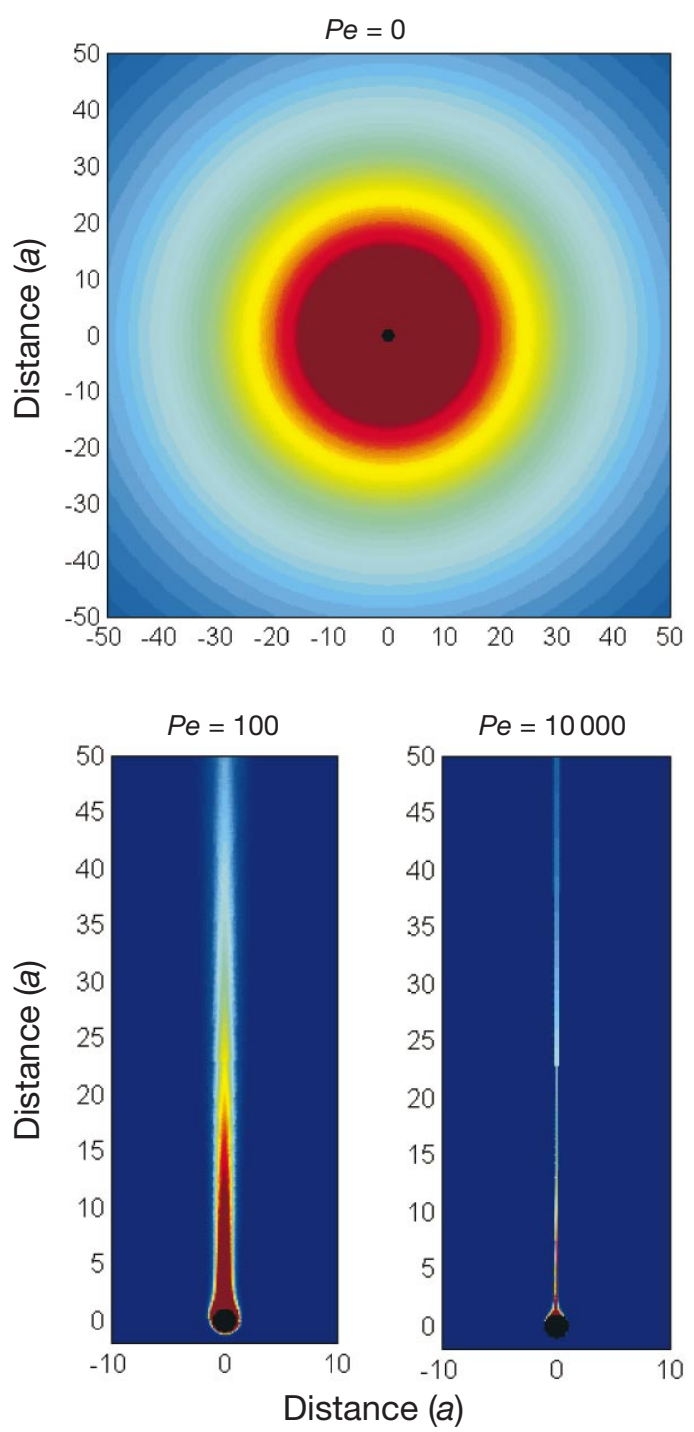

Fig. 3. Spatial distribution of solutes leaking out of a sinking sphere at $P e=0,100$, and 10000 (computed for a Neumann boundary condition) and $R e=P e / 1000$. A $P e=0$ corresponds to pure diffusion. Dark blue corresponds to ambient concentration (assumed $=0$ ), dark red to concentrations exceeding $0.05 \times Q / D a(Q=$ leakage rate, $D=$ diffusion coefficient, $a=$ radius of sphere). All distances are in units of sphere radii (a) 
Table 2. Computed encounter volume rates $\left(\mathrm{ml} \mathrm{s}^{-1}\right.$ copepod $\left.^{-1}\right)$ of aggregates by different mechanisms. The default parameter values given in Table 1 are used. Where relevant, computations were made employing the 2 different relations between aggregate sinking velocity and size (Eqs. 7a \& 7b)

\begin{tabular}{|c|c|c|c|}
\hline \multirow[t]{2}{*}{ Mechanism } & \multirow[t]{2}{*}{ Equation } & \multicolumn{2}{|c|}{ Estimated encounter volume rate $\left(\mathrm{ml} \mathrm{s}^{-1}\right.$} \\
\hline & & $a=0.1 \mathrm{~cm}$ & $a=1.0 \mathrm{~cm}$ \\
\hline Observed encounter volume rate & $12.5 a(\mathrm{~cm})^{2.27}$ & $6.7 \times 10^{-2}$ & 12.5 \\
\hline No perception, cruising copepod & $\pi a^{2} V$ & $3.1 \times 10^{-3}$ & 0.31 \\
\hline \multirow[t]{2}{*}{ No perception, scavenging aggregate } & $1.5 \pi r^{2} U$ & Eq. $7 \mathrm{a}: 8.4 \times 10^{-4}$ & $1.5 \times 10^{-3}$ \\
\hline & & Eq. 7 b: $2.4 \times 10^{-4}$ & $2.4 \times 10^{-3}$ \\
\hline \multirow[t]{2}{*}{ Hydromechanical perception, stationary copepod } & $\pi R^{2} U$ & Eq. 7 a: $9.3 \times 10^{-3}$ & 0.72 \\
\hline & & Eq. 7 b: $2.6 \times 10^{-3}$ & 1.1 \\
\hline \multirow[t]{2}{*}{ Chemical perception, cruising copepod ${ }^{\mathrm{a}}$} & $A v$ & Eq. 7 a: $4 \times 10^{2}$ & 12.7 \\
\hline & & Eq. 7 b: $7.4 \times 10^{-2}$ & 14.3 \\
\hline
\end{tabular}

\section{ZOOPLANKTON COLONIZATION RATES}

Before examining potential detection and encounter mechanisms, we first summarize observations of colonization rates with which model predictions can be compared. Kiørboe (2000) compiled the available information on the abundance of zooplankters sitting on aggregates (no. aggregate ${ }^{-1}$ ) in surface waters and found that normalized abundances $\left(N_{\mathrm{A}}, \mathrm{ml}\right.$ aggregate $^{-1}$ ), which were obtained by dividing absolute abundances with ambient animal concentrations (no. $\mathrm{ml}^{-1}$ ), scaled approximately with aggregate radius (a) square $-N_{\mathrm{A}}\left(\mathrm{ml}\right.$ aggregate $\left.{ }^{-1}\right)=2240 a(\mathrm{~cm})^{2.27}$. Most colonizing crustaceans appear to reside on individual aggregates only for short periods of time before they swim away to find a new aggregate (Alldredge 1972, Shanks \& Walters 1997). Shanks \& Walters (1997) estimated an average residence time of $3 \mathrm{~min}$. By dividing normalized abundance by average residence time, an average 'encounter volume rate' $\left(\beta, \mathrm{ml} \mathrm{s}^{-1}\right)$ can be estimated:

$$
\beta\left(\mathrm{ml} \mathrm{s}^{-1}\right)=N_{\mathrm{A}} / 180 \mathrm{~s}=12.5 a(\mathrm{~cm})^{2.27}
$$

Thus, the encounter rate of a $0.1 \mathrm{~cm}$ radius aggregate is about $\left(0.067 \mathrm{ml} \mathrm{s}^{-1}=\right) 0.25 \mathrm{l} \mathrm{h}^{-1}$ and of a $1 \mathrm{~cm}$ aggregate $\left(12.5 \mathrm{ml} \mathrm{s}^{-1}=\right) 45 \mathrm{l} \mathrm{h}^{-1}$ (Table 2$)$. Depending on the encounter mechanism, the encounter volume rate can be interpreted as the volume of water that a sinking aggregate scavenges for zooplankters per unit time, or as the volume of water that an individual zooplankter searches for aggregates per unit time (akin to clearance rate). The rate at which an individual zooplankter encounters aggregates is given by $\beta C_{\mathrm{A}}$, and the colonization rate of an aggregate (no. zooplankters arriving per unit time and aggregate) as $\beta C_{Z}$, where $C_{\mathrm{A}}$ and $C_{\mathrm{Z}}$ are the concentrations of aggregates and zooplankters.

\section{ENCOUNTERS WITHOUT REMOTE DETECTION}

Knowing the flow and concentration fields around a sinking aggregate, we can now examine different detection and encounter mechanisms and compare their predictions with Eq. (6) (Table 2). The simplest mechanisms of encounters between sinking marine snow and colonizing zooplankters is either that the sinking aggregate 'scavenges' colonizers as it sinks and that the colonizers can be considered inert (behaviorless) particles, or that a cruising colonizer simply bumps into the aggregate. For the latter mechanism, the encounter volume rate is simply $\pi a^{2} v$, where $V$ is the cruising velocity of the colonizer. For a typical $v$ of a $1 \mathrm{~mm}$ sized copepod of $1 \mathrm{~mm} \mathrm{~s}^{-1}$, this yields estimates that are 1 to 2 orders of magnitude less those estimated by Eq. (6) (Table 2).

To estimate encounter volume rates by scavenging we need to know aggregate sinking velocities $(U)$. Alldredge \& Gotschalk $(1988,1989)$ made in situ observations of sinking velocities of aggregates of various sizes, and provided the following empirical relationships between sinking velocity and equivalent radius:

$$
\begin{aligned}
& U\left(\mathrm{~cm} \mathrm{~s}^{-1}\right)=0.13 a(\mathrm{~cm})^{0.26} \\
& \quad(\text { Alldredge \& Gotschalk 1988) } \\
& U\left(\mathrm{~cm} \mathrm{~s}^{-1}\right)=0.2 a(\mathrm{~cm}) \\
& \quad(\text { Alldredge \& Gotschalk 1989) }
\end{aligned}
$$

These relations differ mainly in their scaling, but provide sinking rate estimates of similar magnitudes for aggregates in the size range typical for (most) marine snow, 0.1 to $1 \mathrm{~cm}$ radius. Other relations mainly yielding lower sinking velocities have been reported in the literature. For example, direct in situ estimates provided by Asper (1987) and Pilskaln et al. (1998) for 
1 to $5 \mathrm{~mm}$ diameter aggregates are 3 to 50 times lower than those predicted by Eq. (7). We shall use the above relations and, by sensitivity analysis, demonstrate that the below conclusions are conservative if sinking velocities are in fact lower.

A first, upper, estimate of the encounter volume rate due to scavenging is $\pi a^{2} U$, which combined with Eq. (7a) yields approximately the correct scaling but again gives estimates that are 1 to 2 orders of magnitude less those predicted by Eq. (6). These are upper estimates, however, because hydrodynamic effects have been ignored. A sinking aggregate pushes the ambient water around itself, and taking this effect into account, significantly changes the scaling and reduces the estimated encounter volume rate, particularly for the larger particles. The encounter volume rate in this situation is the volume flow of water passing the aggregate within a distance $r$, where $r$ is the radius of the colonizer. If we assume Stokes' flow around the sinking aggregate (i.e., low $R e$ ), an analytical solution exists, and the encounter volume rate becomes $\sim 1.5 \pi r^{2} U$ (Spielman 1977, Kiørboe \& Titelman 1998). For a $1 \mathrm{~mm}$ sized colonizer, this yields estimates that are 2 to 4 orders of magnitude less those predicted by Eq. (6) (Table 2). At higher $R e$, numerically estimated rates are slightly higher than those estimated for Stokes' flow, e.g., a factor of 4 at $R e=20$, a $0.1 \mathrm{~cm}$ copepod and a $1 \mathrm{~cm}$ (radius) aggregate, but still 3 orders of magnitude less that predicted by Eq. (6). Lower aggregate sinking velocities than those assumed (Eq. 7) yield lower encounter volume rates.

The above considerations thus suggest that remote detection is required to account for the observed abundances of colonizing zooplankters on marine snow aggregates.

\section{HYDROMECHANICAL PERCEPTION}

Copepods are equipped with mechanosensory setae extending in particular from the antennae. Neurophysiological studies have revealed that bending of these setae may elicit a neurophysiological response, that the setae are velocity rather than displacement sensors, and that a threshold velocity difference (signal strength) between the copepod and the ambient fluid of about $20 \mu \mathrm{m} \mathrm{s}^{-1}$ is required to elicit a neurophysiological response (Yen et al. 1992). Experiments have demonstrated that signal strength several orders of magnitude higher is required to elicit escape responses in copepods (Kiørboe et al. 1999). Attack responses appear to be elicited at signal strengths closer to the neurophysiological limit, e.g., $40 \mu \mathrm{m} \mathrm{s}^{-1}$ in Oithona similis, a copepod with particularly long setae (Svensen \& Kiørboe 2000), and about an order of magnitude higher in the predatory copepod Centropages typicus (Titelman 2001). A copepod will be entrained in the fluid flow generated by a moving particle if this is much larger than the copepod. Velocity gradients in this flow will cause a velocity difference between the copepod and the ambient fluid that, in turn, will cause extending setae to bend. Specifically, the copepod responds to the fluid deformation rate $(\Delta)$, and the signal strength is $S=\Delta r$, where $r$ is the equivalent radius of the copepod (Kiørboe \& Visser 1999, Kiørboe et al. 1999).

Consider now a mm-sized copepod. If we conservatively assume a threshold signal strength for a behavioral response of $S^{*}=40 \mu \mathrm{m} \mathrm{s}^{-1}$, then the threshold deformation rate required for perception is $\left(S^{*} / r=\right.$ $40 / 500 \mathrm{~s}^{-1}=$ ) $0.08 \mathrm{~s}^{-1}$. Fig. $4 \mathrm{~A}$ shows the $0.08 \mathrm{~s}^{-1}$ isoline for an aggregate at $R e=5$, corresponding to an aggregate of radius $0.5 \mathrm{~cm}$ with a settling velocity of $0.1 \mathrm{~cm}$ $\mathrm{s}^{-1}$ (Eqs. 7a,b). Assume now that the colonizing copepod utilizes an ambush strategy, i.e., it sits motionless in the water column waiting for fluxing particles to pass by within a distance at which they can be perceived. The horizontal extension of the deformation field then becomes what matters, and the encounter volume rate is given by $\pi R^{2} U$, where $R$ is the perception distance or half the horizontal extension of thresh-
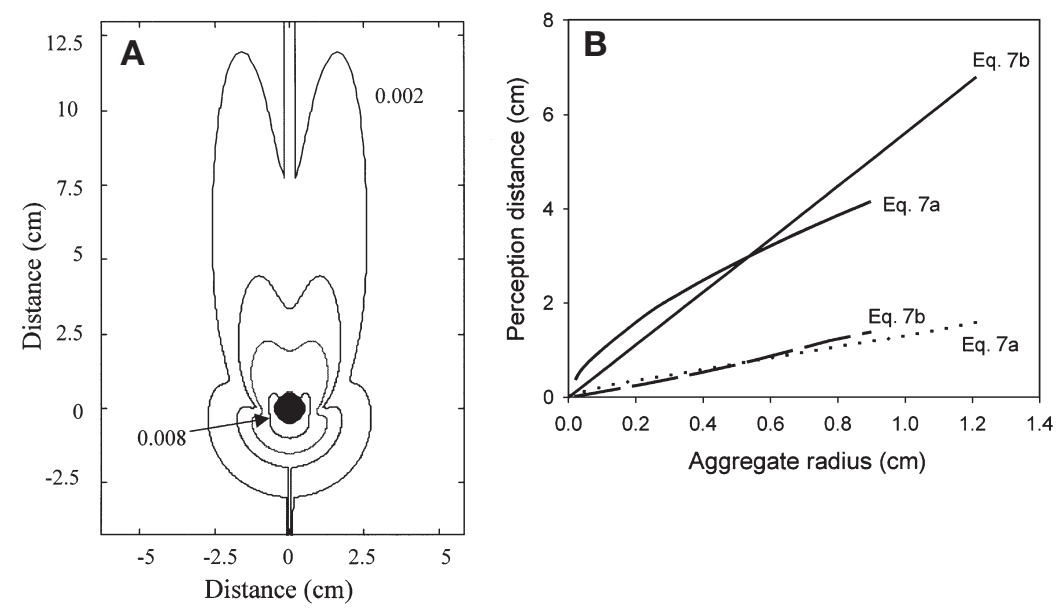

Fig. 4. (A) Deformation field for a of $0.5 \mathrm{~cm}$ radius sphere sinking at $0.1 \mathrm{~cm} \mathrm{~s}^{-1}$ $(R e=5)$. The isolines are $0.002,0.008,0.02$, and $0.08 \mathrm{~s}^{-1}$ and depict the distance at which a $1 \mathrm{~mm}$ copepod can perceive a sinking aggregate, provided it has a threshold sensitivity, $S^{*}$, of $1,4,10$, or $40 \mu \mathrm{m} \mathrm{s}^{-1}$, respectively. (B) The detection distances required to account for encounter volume rates computed from observed abundances of zooplankters on aggregates (solid lines), as well as those computed assuming a threshold sensitivity of $40 \mu \mathrm{m} \mathrm{s}^{-1}$ for a $1 \mathrm{~mm}$ copepod (dotted lines), both as a function of aggregate size. Computations have been made assuming 2 different size-sinking velocity relations 
old deformation isoline. (For simplicity and to be conservative, in computing the encounter volume rate we ignore that the fluid motion generated by the sinking aggregate will move the colonizer slightly.) In our example, this corresponds to a detection distance (measured from the center of the particle) of $0.7 \mathrm{~cm}$, i.e., only slightly more than the particle's radius. The detection distance required to account for the encounter volume rate predicted by Eq. (6) is $2.9 \mathrm{~cm}$, or 4 times higher. A detection distance of this order would require a threshold deformation rate of $0.002 \mathrm{~s}^{-1}$, or a threshold signal strength of $1 \mu \mathrm{m} \mathrm{s}^{-1}$, i.e., more than an order of magnitude less the neurophysiological limit. A similar analysis for a range of particle sizes (Fig. 4B, Table 2) generalizes this conclusion. Decreasing the encounter volume rate estimated from Eq. (6) by an order of magnitude relaxes the sensitivity requirement to $25 \mu \mathrm{m} \mathrm{s}^{-1}$, i.e., close to the neurophysiological limit. Decreasing the particle sinking velocity by a factor of 10 decreases the required threshold sensitivity to $10^{-2} \mu \mathrm{m} \mathrm{s}^{-1}$. Even a copepod with a cruising strategy would not benefit much from the deformation rate generated by the sinking particle, because the deformation rate attenuates rapidly in all directions to values unlikely to elicit behavioral responses (Fig. 2).

Copepods that colonize aggregates, mainly harpacticoid copepepods and Poecilostomatoid copepods of the genus Oncaea, are typically characterized by very short antennae (Fig. 1). This morphology appears inconsistent with a high sensitivity to hydrodynamic signals. Our considerations thus suggest that copepods that colonize marine snow aggregates are unlikely to utilize hydrodynamic cues to detect these.

\section{CHEMICAL PERCEPTION}

The long slender plume of solutes left behind the leaking and sinking aggregate (Fig. 3) may be detected by a horizontally cruising copepod. Such a detection mechanism has in fact been demonstrated for the planktonic shrimp Acetes sibogae (Hamner \& Hamner 1977). Shrimps encountering the scent trail from a sinking food particle follow the chemical track and capture the particle. A similar mechanism has been described for male copepods Calanus marshallae searching for females (Tsuda \& Miller 1998). The slowly sinking female releases pheromones, thus leaving a plume of maleattractant similar to that shown in Fig. 3. On encountering the pheromone plume, the male swims down the chemical trail to find the female. These situations resemble the one we have in mind here.

Aggregates do not release pheromones, but leak DOM. In order to examine the potential for chemical perception we need first to consider likely components of DOM that copepods may detect, at what rate these components leak out of an aggregate, and at what threshold concentration a copepod may detect and respond to the solute.

\section{Sensitivity to chemical stimuli}

Several studies have demonstrated that crustaceans, including copepods, are very sensitive and respond behaviorally to dissolved amino acids, with response thresholds to specific amino acids being often much less than typical background concentrations of total amino acids. Bulk background concentrations of dissolved amino acids are on order $<10^{-7}$ to $10^{-9} \mathrm{M}$ in surface waters, less at depth (Mopper \& Lindroth 1982, Carlucci et al. 1984, Poulet et al. 1991). Behavioral responses in crabs have been recorded at amino acid concentrations as low as $10^{-12}$ to $10^{-20} \mathrm{M}$ (Fuzessery \& Childress 1975, Pearson \& Olla 1977, Thomson \& Ache 1980). In copepods, neurophysiological responses in Undinula sp. have been observed at concentrations of the amino acid serine down to $10^{-9} \mathrm{M}$ (Yen et al. 1998). Amino acids at concentrations of $10^{-5} \mathrm{M}$ may induce swarming behavior in Eurytemora herdmani (Poulet \& Ouellet 1982), and Gill \& Poulet (1988) reported that enhanced beat frequency of the first maxilla - a more direct index of feeding behavior-occurred at concentrations of $\leq 10^{-6} \mathrm{M}$, but not at $10^{-8} \mathrm{M}$, in Temora longicornis. There are likely to be major species-specific differences in sensitivity, and motor responses in the more sensitive copepods may therefore be expected at amino acid concentrations down to $10^{-7}-10^{-9} \mathrm{M}$ or less.

\section{Leakage of amino acids from aggregates}

Marine snow aggregates do leak amino acids (Smith et al. 1992, Grossart \& Simon 1998, Vetter et al. 1998). Bacteria attached to marine snow aggregates hydrolyse particulate substances to solute monomers faster than these are taken up by the bacteria (Smith et al. 1992) and solutes hence leak out of the aggregate. Based on Smith et al. (1992), an estimate of the leakage of free amino acid- $\mathrm{N}$ as a fraction of aggregate $\mathrm{N}$ is about $0.2 \mathrm{~d}^{-1}$. Alldredge (1998) gives the size-dependent nitrogen content of marine snow aggregates as $\operatorname{PON}(\mathrm{mol} \mathrm{N})=6.3 \times 10^{-7} r^{1.5}(\mathrm{~cm})$. Because $1 \mathrm{~mol} \mathrm{~N} \cong$ $0.75 \mathrm{~mol}$ amino acid, the size-dependent amino acid leakage $(Q)$ rate becomes:

$$
Q\left(\mathrm{~mol} \text { amino acid } \mathrm{s}^{-1}\right) \cong 10^{-12} r^{1.5}(\mathrm{~cm})
$$

The actual exudation rates measured by Smith et al. (1992) in 'larger than $2 \mathrm{~mm}$ diameter' aggregates, 0.3 to $0.8 \mathrm{nmol}$ aggregate $\mathrm{h}^{-1}$, are somewhat higher than 
that estimated by Eq. (8) for $2 \mathrm{~mm}$ diameter aggregates, $0.11 \mathrm{nmol}$ aggregate $\mathrm{h}^{-1}$. Grossart \& Simon (1998) provided the only other measurements of amino acid leakage rates in sinking aggregates, and found that $0.27 \mathrm{~cm}$ (radius) aggregates leak between 0.45 and $2.25 \mathrm{nmol}$ amino acid $\mathrm{h}^{-1}$. This is consistent with that predicted by Eq. (8), $0.6 \mathrm{nmol} \mathrm{h}^{-1}$. (The numbers given in Grossart \& Simon were wrong, but have been corrected here; Grossart pers. comm.)

We may first examine whether the solute concentration produced by a leaking and sinking aggregate is sufficiently high to elicit motor responses. It can be shown from the diffusion-advection equation that the surface concentration of solutes is

$$
C_{r=a}=\frac{Q}{4 \pi D a S h}
$$

where $S h$ is the dimensionless Sherwood number and $C_{r=a}$ the surface concentration. Combining Eqs. (8) \& (9) and the Sh numbers computed by Kiørboe et al. (2001), yields surface concentration as a function of particle size (Fig. 5A; here employing a Dirichlet boundary condition). For aggregates with a radius less than ca $0.02 \mathrm{~cm}$, surface concentration drops rapidly with decreasing particle size, suggesting that there is a minimum particle size for chemical detection. For bigger particles, however, the surface concentration is largely independent of particle size and close to $5 \times$ $10^{-7} \mathrm{M}$. Employing instead a Neumann boundary condition yields even higher surface concentrations in the downstream direction. This suggests that there is a potential for chemical detection.

\section{Encountering the plume}

The rate at which a cruising copepod encounters chemical plumes from aggregates depends on the vertical cross-sectional area of the plume with concentrations exceeding the threshold $(A)$ multiplied by the horizontal swimming velocity of the copepod $(v)$ and the concentration of aggregates. The encounter volume rate is $A \times v$. Assuming $v=1 \mathrm{~mm} \mathrm{~s}^{-1}$ we have computed the area required to account for the encounter volume rates predicted by Eq. (6) and in Fig. 5B depicted the threshold concentration that yields that area. Almost independent of particle size, the threshold concentration required is on order $4 \times 10^{-8} \mathrm{M}$. Varying the default parameter values of swimming velocity, leakage rate, and encounter volume rate over an order of magnitude (i.e., from $\times 1 / 3$ to $\times 3$ the default values) yield required threshold concentrations of the same order, with required threshold concentration being most sensitive to variation in leakage rate (Table 3). Decreasing the aggregate sinking velocity
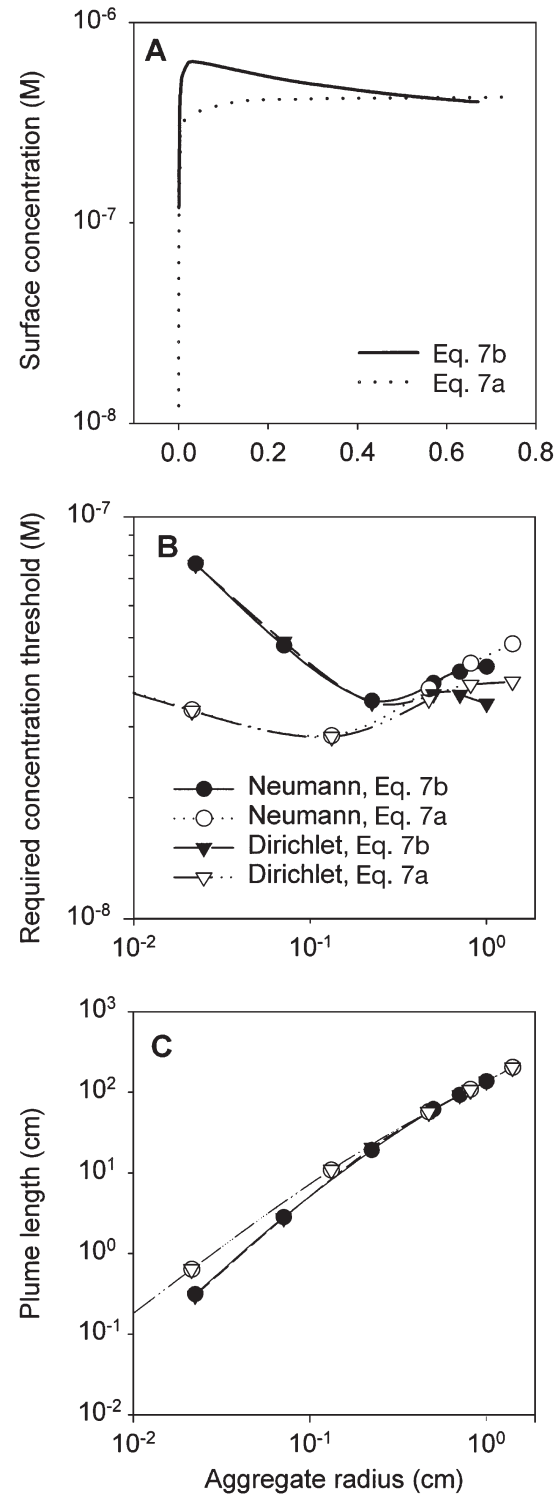

Fig. 5. (A) Amino acid concentration at the surface of an aggregate as a function of size. Computed for a Dirichlet boundary condition and 2 sinking velocity-size relations (Eq. 7). The threshold amino acid concentration required to yield a transsectional plume area sufficient to account for the encounter volume rates computed from abundances of zooplankters on aggregates. Assumptions are either a Dirichlet or a Neumann boundary condition, and either of the 2 sinking velocity-size relations (Eq. 7). Leakage rate according to Eq. (8). (C) Length of the plume as a function of aggregate size

by a factor of 10 increases the required threshold concentration by $50 \%$. The independence of the estimated threshold of particle size implies that the scaling is correct.

The length of the plume holding concentrations exceeding the threshold increases with aggregate size (Fig. 5C) and reaches about $1 \mathrm{~m}$ in length ( 100 particle radii) for a $1 \mathrm{~cm}$ radius aggregate. 
Table 3. Effect of varying parameter values from $\times 1 / 3$ to $\times 3$ of their default values (horizontal swimming velocity $0.1 \mathrm{~cm} \mathrm{~s}^{-1}$, leakage rate: Eq. 8; encounter volume rate: Eq. 6) on the estimated threshold concentration $\left(C^{*}\right)$ of amino acids required to elicit a behavioral response to a $0.5 \mathrm{~cm}$ radius sinking aggregate. The effect is expressed as the estimated range in $C^{*}$ over the applied change in parameter value

\begin{tabular}{|lcccc|}
\hline Parameter changed & None & Swimming velocity & Leakage rate & Encounter volume rate \\
\hline Range in estimated $C^{*}, \mathrm{M}$ & $4 \times 10^{-8}$ & $2.4-7 \times 10^{-8}$ & $1.1-11.4 \times 10^{-8}$ & $2.4-7 \times 10^{-8}$ \\
\hline
\end{tabular}

\section{DISCUSSION AND CONCLUSIONS}

All the encounter mechanisms examined here, except for scavenging, yield scalings of encounter volume rate with aggregate size that are consistent with the observed scaling of the abundances of colonizers on aggregates. The encounter volume rates inferred from observed abundances suggest that remote detection is required for colonizers to encounter aggregates. This suggestion hinges, however, on the estimated short average residence of zooplankters on the aggregates. Longer residence times would relax the requirements for remote detection. The 3 min residence time reported by Shanks \& Walters (1997) is based on laboratory experiments, but is consistent with observations of Alldredge (1972), who noted that Oncaea mediterranea feeding on aggregates were highly active but spent only little of their time $(5 \%)$ actually on the aggregates. One may ask why a small zooplankter that has just succeeded to locate a rich feeding environment in the form of an aggregate would bother to leave this so soon again, just to spend time finding a new one? This would at first appear inconsistent with predictions from optimal foraging theory, unless different aggregates provide very different feeding environments, and the animals would need to test many aggregates until eventually finding a nutritious one. However, in any particular environment, aggregates are probably more similar than they are different, because one source of aggregates would typically dominate (e.g., diatom aggregates during diatom blooms; marine snow formed from abandoned larvacean houses when larvaceans are dominant) (Alldredge \& Gotschalk 1990).

While aggregates provide luxurious feeding microhabitats, they may also constitute a risky environment, because fish, euphausids, and other macrophageous predators may feed on aggregates and their inhabitants. If the predation risk is higher for a zooplankter sitting on an aggregate than for one swimming in the ambient water, then the zooplankter should seek refuge away from the aggregate as soon as it has filled its gut. Filling the gut may in fact only take a few minutes when food is plentiful. For this strategy to be viable, however, the chance of finding a new aggre- gate when ready to fill the gut again should be high. To be more exact, the encounter frequency with aggregates should be higher than or of the same order as gut turnover time. In surface waters, abundances of $>3 \mathrm{~mm}$ aggregates are typically 1 to $10 \mathrm{l}^{-1}$ (Alldredge \& Silver 1988), and encounter frequencies estimated as encounter volume rate (Eq. 6) multiplied by aggregate concentration would therefore be $>0.6$ to $6 \mathrm{~h}^{-1}$ (to be conservative). This is in fact very similar to gut turnover times for small copepods, e.g., $3 \mathrm{~h}^{-1}$ in Acartia tonsa at $14^{\circ} \mathrm{C}$ (Kiørboe \& Tiselius 1987). Thus, the short residence time may make sense. Since the optimal residence time is a trade-off between differential mortality rates, gut filling and turnover times, and aggregate encounter frequency, residence times are likely to vary between environments. At depth, there are typically fewer aggregates, yielding lower encounter frequencies. This may be (partly?) compensated by the lower temperatures at depth, which would increase gut turnover times $\left(Q_{10} \approx 3\right.$, Kiørboe et al. 1982, Dam \& Peterson 1988). Thus, the optimal residence time may not change much with depth.

If we accept that remote detection is required, we shall finally consider the nature of the cue that allows colonizers to locate sinking aggregates at distance. Our considerations suggest that hydromechanical signals are too weak to provide remote cues to colonizers. This leaves us with chemical cues. As evident from Fig. 3, the volume of water with elevated solute concentrations - or the plume transsectional areadecreases as a function of the sinking velocity of the aggregate. For the 3 Pe shown in Fig. 3 (0, 100, 10 000), for example, the relative transsectional areas of the $0.005(\times Q / D a)$ isoline (dark red area) are 1, 0.02, and 0.005 , i.e., sinking washes the chemical signal away! On the other hand, sinking is a prerequisite for remote chemical detection, because the time scales associated with setting up the plumes are radically different when solute transport is solely by diffusion $(P e=0)$ or facilitated by advection $(P e>0)$. The diffusion time scale is $\sim L^{2} / D$, where $L$ is the diffusion distance. Thus, the time required for the chemical signal to reach 1 radius outside the particle by diffusion is $\sim 10^{5} \mathrm{~s}$ for a $1 \mathrm{~cm}$ aggregate, and it increases with the square of the distance, e.g., to $\sim 2.5 \times 10^{6} \mathrm{~s}=4 \mathrm{wk}=$ generation time 
for a copepod at 5 particle radii. The time scale for the chemical signal to be set up by a sinking aggregate depends mainly on the ratio of plume length to sinking velocity. Thus, the times required to establish the gradient out to 1 and 5 radii downstream in a sinking aggregate are about 5 and $25 \mathrm{~s}$ (cf. Eq. 7). Thus, chemical detection of large aggregates requires that these sink!

The estimated amino acid threshold concentrations required to account for the estimated encounter volume rates $\left(10^{-7}\right.$ to $\left.10^{-8} \mathrm{M}\right)$ are not inconsistent with neurophysiological observations in copepods and other crustaceans (see also Yen et al. 1998). Some crustaceans have demonstrated neurophysiological and motor responses to concentrations of specific amino acids that are many orders of magnitude less than the threshold concentration estimated here. Also, precise tracking of trails of pheromones (Yen et al. 1998) and amino acids (authors' unpubl. obs.) have been demonstrated in copepods, and the general mechanism suggested here, that cruising copepods encounter a plume of elevated solute concentration left by a sinking particle, has actually been documented to work for copepods seeking mates (Tsuda \& Miller 1998). Tsuda \& Miller (1998) found that males could detect sinking females at a distance of $50 \mathrm{~cm}$ or more downstream, equivalent to ca 130 bodylengths. This is consistent with the plume lengths suggested by the present analysis. However, 2 problems need consideration, namely the resistance (or possible lack thereof) of such long plumes to ambient turbulence, and the apparently low signal-to-noise ratio of the chemical signal.

The time scale to set up the chemical gradient in the $1 \mathrm{~m}$ long plume of a $1 \mathrm{~cm}$ aggregate is about $10 \mathrm{~min}$. One could imagine that strong turbulence would lead to the rapid dissipation of such long plumes. Direct observations in the ocean of plumes left by small sinking particles leaking fluorescent dye suggest that plumes may in fact be that long (or longer) and persistent during calm conditions, in the thermocline, and at depth (Woods 1968, 1971). Moderate shear may cause the plume to meander, and moderate turbulence would cause the plume to become filamentous. Because of the coherent nature of turbulence, this would not necessarily reduce plume concentrations much, but rather cause the chemical cue to be more variable in both time and space than Fig. 3 indicates. Crabs may still be able to locate prey from the chemical signals carried by a meandering and filamentous plume (Zimmer-Faust et al. 1995). The observations of colonizer abundances on aggregates used to generate Eq. (6) were collected under calm enough conditions to allow diving. It is conceivable, however, that strong turbulence in the surface layer would dissipate the plume and prevent remote chemical detection. If zooplankters do use chemical cues to localize sinking aggregates, one would therefore expect lower colonization rates in the upper ocean during turbulent conditions.

The threshold amino acid concentrations estimated here are of the same order as background concentrations of bulk amino acids, at least in the upper ocean of rich environments. High background concentrations may mask the chemical signals from a sinking aggregate. Bulk amino acid concentrations may, however, not be the only parameter of interest, but the quality of the chemical signal may be relevant as well (Ache 1988). That is, the composition or the occurrence of specific amino acids may allow discrimination from background, even though bulk amino acid concentrations are not very different. This is likely the way the extremely low response threshold concentrations of specific (combinations of) amino acids - orders of magnitude less than bulk background concentrationsthat have been recorded in several crustaceans should be understood. Crabs and lobsters, for example, appear to be particularly sensitive to taurine, an amino acid characteristic of animal tissue (response threshold $<10^{-20} \mathrm{M}$, Thomson \& Ache 1980). The amino acid signature of an aggregate is likely to be different from the background signature. Important components of marine snow aggregates are phytoplankton cells, fecal pellets and detritus. While the amino acid composition of copepod fecal pellet largely reflects the composition of the food, both may be radically different from the background (Poulet et al. 1986).

This study has demonstrated that chemosensory localization of sinking aggregates by colonizing copepods is, in principle, possible. However, observations are required to test the hypothesis. The biology of the kinds of copepods, such as Oncaea spp., that colonize snow aggregates is very poorly known. The Oncaea genus is widespread and abundant and sometimes even numerically dominates the mesozooplankton, particularly at depth and below the euphotic zone (e.g., Pancucci-Papadopoulou et al. 1992, BöttgerSchnack 1997). They may play a major role in the degradation of marine snow and, hence, in regulating vertical material fluxes in the ocean. Yet, biological and behavioral observations are very few (Paffenhöfer 1993, Go et al. 1998, Metz 1998). This study suggests that observations of sensitivities to hydromechanical and chemical cues, gut filling and gut throughput times, and swimming behavior are required to further explore the association between these copepods and marine snow aggregates and their significance in regulating vertical material transport in the ocean.

Acknowledgements. We benefited from discussions with George Jackson. The work was supported by a grant from the Danish Natural Science Research Council (9801391). 


\section{LITERATURE CITED}

Ache BW (1988) Integration of chemosensory information in aquatic invertebrates. In: Atema J, Fay RR, Popper AN, Tavolga WN (eds) Sensory biology of aquatic animals. Springer-Verlag, New York, p 386-401

Alldredge AL (1972) Abandoned larvacean houses: a unique food source in the pelagic environment. Science 177:885-887

Alldredge AL (1976) Discarded appendicularian houses as asources of food, surface habitats, and particulate organic matter in planktonic environments. Limnol Oceanogr 21: $14-23$

Alldredge AL (1998) The carbon, nitrogen and mass content of marine snow as a function of aggregate size. Deep-Sea Res 45:529-541

Alldredge AL, Gotschalk C (1988) In situ settling behaviour of marine snow. Limnol Oceanogr 33:339-351

Alldredge AL, Gotschalk C (1989) Direct observations of the mass flocculation of diatom blooms: characteristics, settling velocity and formation of diatom aggregates. DeepSea Res 36:159-171

Alldredge Al, Gotschalk C (1990) The relative contribution of marine snow of different origins to biological processes in coastal waters. Cont Shelf Res 10:41-58

Alldredge AL, Silver MW (1988) Characteristics, dynamics and significance of marine snow. Prog Oceanogr 20:42-82

Asper VL (1987) Measuring the flux and sinking speed of marine snow aggregates. Deep-Sea Res 34:1-17

Banse K (1990) New views on the degradation and deposition of organic particles as collected by sediment traps in the open sea. Deep-Sea Res 37:1177-1195

Böttger-Schnack R (1997) Vertical structure of small metazoan plankton, especially non-calanoid copepods. II. Deep Eastern Mediterranean (Levantine Sea). Oceanol Acta 20: 399-419

Carlucci AF, Craven DB, Henrichs SM (1984) Diel production and microheterotrophic utilization of dissolved amino acids in waters off Southern California. Appl Environ Microbiol 48:165-170

Dam HG, Peterson WT (1988) The effect of temperature on the gut clearance rate constant of planktonic copepods. J Exp Mar Biol Ecol 123:1-14

Dilling L, Wilson J, Steinberg D, Alldredge A (1998) Feeding by the euphausiid Euphausia pacifica and the copepod Calanus pacificus on marine snow. Mar Ecol Prog Ser 170:189-201

Fields DM, Yen J (1997) The escape behaviour of marine copepods in response to a quantifiable fluid mechanical disturbance. J Plankton Res 19:79-95

Fowler SW, Knauer GA (1986) Role of large particles in the transport of elements and organic compounds through the ocean water column. Prog Oceanogr 16:147-194

Fuzessery ZM, Childress JJ (1975) Comparative chemosensitivity to amino acids and their role in the feeding activity of bathypelagic and littoral crustaceans. Biol Bull 149: 522-538

Gill CW, Poulet SA (1988) Responses of copepods to dissolved free amino acids. Mar Ecol Prog Ser 43:269-276

Go YB, Oh BC, Terazaki M (1998) Feeding behaviour of the poecilostomatoid copepods Oncaea spp. on chaetognaths. J Mar Syst 15:475-482

Grossart HP, Simon M (1998) Bacterial colonization and microbial decomposition of limnetic organic aggregates (lake snow). Aquat Microb Ecol 15:127-140

Hamner P, Hamner WM (1977) Chemosensory tracking of scent trails by the planktonic shrimp Acetes sibogae australis. Science 195:886-888
Karp-Boss L, Boss E, Jumars PA (1996) Nutrient fluxes to planktonic osmotrophs in the presence of fluid motion. Oceanogr Mar Biol Annu Rev 34:71-107

Kiørboe T (2000) Colonization of marine snow aggregates by invertebrate zooplankton: abundance, scaling, and possible role. Limnol Oceanogr 45:479-484

Kiørboe T, Tiselius P (1987) Gut clearance and pigment destruction in a herbivorous copepod, Acartia tonsa, and the determination of in situ grazing rates. J Plankton Res 9:525-534

Kiørboe T, Titelman J (1998) Feeding, prey selection and encounter mechanisms in the heterotrophic dinoflagellate Noctiluca scintillans. J Plankton Res 20:1615-1636

Kiørboe T, Visser A (1999) Predator and prey perception in copepods due to hydromechanical signals. Mar Ecol Prog Ser 179:81-95

Kiørboe T, Møhlenberg F, Nicolajsen H (1982) Ingestion rate and gut clearance rate in the planktonic copepod Centropages hamatus (Liljeborg) in relation to food concentration and temperature. Ophelia 21:181-194

Kiørboe T, Saiz E, Visser A (1999) Hydrodynamic signal perception in the copepod Acartia tonsa. Mar Ecol Prog Ser 179:97-111

Kiørboe T, Ploug H, Thygesen UH (2001) Fluid motion and solute distribution around sinking aggregates. I. Smallscale fluxes and heterogeneity of nutrients in the pelagic environment. Mar Ecol Prog Ser 211:1-13

Lampitt RS, Wishner KF, Turley CM, Angel MV (1993) Marine snow studies in the Northeast Atlantic: distribution, composition and role as food source for migrating plankton. Mar Biol 116:689-702

Larson ET, Shanks AL (1996) Consumption of marine snow by two species of juvenile mullet and its contribution to their growth. Mar Ecol Prog Ser 130:19-28

Martin JH, Knauer GA, Karl DM, Broenkow WW (1987) VERTEX: carbon cycling in the northeast Pacific. Deep-Sea Res 38:267-285

Metz C (1998) Feeding of Oncaea curvata (Poecilostomatoida, Copepoda). Mar Ecol Prog Ser 169:229-235

Mopper K, Lindroth P (1982) Diel and depth variation in dissolved free amino acids and ammonium in the Baltic Sea determined by shipboard HPLC analysis. Limnol Oceanogr 27:336-347

Pace ML, Knauer GL, Karl DM, Martin JH (1987) Primary production, new production and vertical fluxes in the eastern Pacific Ocean. Nature 325:803-804

Paffenhöfer GA (1993) On the ecology of marine cyclopoid copepods (Crustacea, Copepoda). J Plankton Res 15:37-55

Pancucci-Papadopoulou AA, Siokou-Frangou I, Theocharis A, Georgopoulos D (1992) Zooplankton vertical distribution in relation to the hydrology in the NW Levantine and the SE Aegean Seas. Oceanol Acta 15:365-381

Pearson WH, Olla BL (1977) Chemoreception in the blue crab, Callinectes sapidus. Biol Bull 153:346-354

Pilskaln CH, Lehman C, Paduan JF, Silver MW (1998) Spatial and temporal dynamics in marine aggregate abundance, sinking rate and flux: Monterey Bay, central California. Deep-Sea Res II 45:1803-1837

Ploug H, Grossart HP, Azam F, Jørgensen BB (1999) Photosynthesis, respiration and carbon turn-over in sinking marine snow from surface waters of Southern California: implications for the carbon cycle in the ocean. Mar Ecol Prog Ser 179:1-11

Poulet SA, Ouellet G (1982) The role of amino acids in the chemosensory swarming and feeding of marine copepods. J Plankton Res 4:341-361

Poulet SA, Harris RP, Jézéquel VM, Moal J, Samain JF (1986) 
Free amino acids in copepod fecal pellets. Oceanol Acta 9:191-197

Poulet SA, Williams R, Conway DVP, Videau C (1991) Cooccurrence of copepods and dissolved free amino acids in shelf waters. Mar Biol 108:373-385

Shanks AL, Walters K (1997) Holoplankton, meroplankton, and meiofauna associated with marine snow. Mar Ecol Prog Ser 156:75-86

Smith DC, Silver MW, Alldredge AL, Azam F (1992) Intensive hydrolytic activity on marine aggregates and implications for rapid particle dissolution. Nature 359:139-141

Spielman LA (1977) Particle capture from low-speed laminar flows. Annu Rev Fluid Mech 9:297-319

Svensen C, Kiørboe T (2000) Remote prey detection in Oithona similis: hydromechanical vs chemical cues. J Plankton Res 22:1155-1166

Thomson H, Ache BW (1980) Threshold determination for olfactory receptors of the spiny lobster. Mar Behav Physiol $7: 249-260$

Titelman J (2001) Swimming and escape behaviour of copepod nauplii: implications for predator-prey interactions among copepods. Mar Ecol Prog Ser (in press)

Editorial responsibility: Otto Kinne (Editor),

Oldendorf/Luhe, Germany
Tsuda A, Miller CB (1998) Mate-finding behaviour in Calanus marshallae Frost. Phil Trans R Soc Lond B 353: 713-720

Vetter YA, Deming JW, Jumars PA, Krieger-Brockett BB (1998) A predictive model of bacterial foraging by means of freely released extracellular enzymes. Microb Ecol 36: 75-92

Woods JD (1968) Wave-induced shear instability in the summer thermocline. J Fluid Mech 32:791-800

Woods JD (1971) Micro-oceanography. In: Woods JD, Lythgoe JN (eds) Underwater science. An introduction to experiments by divers. Oxford University Press, London, p 291-317

Yen J, Lenz PH, Gassie DV, Hartline DK (1992) Mechanoreception in marine copepods: electrophysiological studies on the first antennae. J Plankton Res 14:459-512

Yen J, Weissburg MJ, Doall MH (1998) The fluid physics of signal perception by mate-tracking copepods. Phil Trans R Soc Lond B 353:787-804

Zimmer-Faust RK, Finelli CM, Pentcheff ND, Wethey DS (1995) Odor plumes and animal navigation in turbulent water flow: a field study. Biol Bull 188:111-116

Submitted: March 20, 2000; Accepted: August 3, 2000 Proofs received from author(s): January 11, 2001 